

\title{
Effect of Different Resin Thickness on Some Physical Properties of Sonic Fill Versus Bulk Fill Resin Composite
}

\author{
Omnia M. Nour ${ }^{*}$, Maha A. Niazy $^{2}$, Sameh M. Nabih $^{3}$
}

Codex : 62/20.10

azhardentj@azhar.edu.eg

http://adjg.journals.ekb.eg

DOI: $10.21608 /$ adjg.2020.9669.1130

Restorative Dentistry

(Removable Prosthodontics, Fixed

Prosthodontics, Endodontics, Dental Biomaterials, Operative Dentistry)

\section{KEYWORDS}

Bulk fill, resin thickness,

conversion, strain gauge.

\begin{abstract}
Purpose: This study evaluated the effect of resin thickness from both $\{$ Sonic Fill resin composite (SF)\& Tetric N Ceram Bulk Fill resin composite (TNB)\} on polymerization shrinkage strains, depth of cure and degree of conversion. Material and Methods: A total of 70 specimens were prepared and Polymerization shrinkage strains were measured by strain gauge foil connected to the computer software program which gave the results. Depth of cure (DOC) was measured by Vickers microhardness tester applying a $50 \mathrm{~g}$ load through a Vickers indenter with a dwell time of $10 \mathrm{~s}$ and expressed as mean of hardness ratio. Degree of conversion (DC\%) was measured using Fourier transform infrared spectroscopy by potassium bromide pellet technique. All recorded data were presented, tabulated and statistically analyzed. Results: the strains resulted from both materials increased with increasing the thickness of the specimens from $2 \mathrm{~mm}$ to $4 \mathrm{~mm}$ but decreased at $6 \mathrm{~mm}$. There was a statistically significant increase in depth of cure and degree of conversion in SF than in TNB at all specimen thickness. Conclusions: Bulk fill resin composite in thickness more than $4 \mathrm{~mm}$ affect the physical properties; degree of conversion, depth of cure and polymerization shrinkage.
\end{abstract}

\section{INTRODUCTION}

Resin composite successfully used in dentistry for many years and widely replaced amalgam as a posterior restoration, it has been regarded as the gold standard to apply and cure the resin composite in maximal increment thickness of $1.5-2 \mathrm{~mm}^{(1)}$. When restoring cavities, characterized by deep depth, with resin composite increments of $2 \mathrm{~mm}$ thickness is time wasting and increase a risk of incorporating air bubbles

- Paper extracted from $\mathrm{PhD}$ thesis titled: Effect of different resin thickness on some physical properties and clinical performance of sonic fill versus bulk fill resin composite.

1. Second doctor in Restorative Dentistry Department, Faculty of Dental Medicine, Alexandria University, Egypt

2. Professor of Operative Dentistry, Faculty of Dental Medicine for Girls, AL-Azhar University, Cairo, Egypt

3. Professor of Operative Dentistry, Faculty of Dental Medicine for Boys, AL-Azhar University, Cairo, Egypt

* Corrsponding author email: dr.omnianour80@gmail.com 
between the increments ${ }^{(2)}$. New category of composite resin, called "bulk fill" materials, which are claimed to be able to cure to a maximal layer thickness of $4 \mathrm{~mm}$ or more ${ }^{(3)}$. There are some concerns regarding bulk fill resin composite; First, rationale for limiting composite increments to $2 \mathrm{~mm}$ is to allow the curing light to penetrate to the resin farthest away from the light source ${ }^{(4)}$. Energy of the light from a light-curing unit decreases to a great extent as going through resin composite, leading to decrease in degree of conversion which compromise physical properties and increase release of mono$\mathrm{mer}^{(5)}$. A second reason for using 2-mm increments, is to minimize the shrinkage and shrinkage resulted stress associated with resin composite polymerization $^{(6)}$. On the other hand; manufacturers claim that bulk fill materials have good physical properties ${ }^{(3)}$. The null hypotheses tested was as follow: (1) There is no difference between Sonic Fill resin composite and Tetric N Ceram bulk fill resin composite in polymerization shrinkage, depth of cure, and degree of conversion at difference resin thickness.

\section{MATERIAL AND METHODS}

Table (1): Materials used in this study, composition, manufacture, as well as their lot number.

\begin{tabular}{|c|c|c|c|}
\hline Materials & Composition & Manufacture & Lot number \\
\hline Sonic Fill Bulk Fill. & $\begin{array}{l}\text { 3-trimethoxysilypropyl methacrylate }(10-30 \%) \text {; sili- } \\
\text { cone dioxide }(5-10 \%) \text {; ethoxylated bisphenol-A- di- } \\
\text { methacrylate (Bis-EMA:1-5\%); bisphenol-A-bis-(2- } \\
\text { hydroxy-3-methacryloxypropyl) ether }(1-5 \%) \text {; trieth- } \\
\text { ylene glycol dimethacrylate (TEGDMA:1-5\%). } \\
\text { Filler: Silicon dioxide, barium glass. } \\
\text { Filler load: }(83.5 \% \text { weight);( -volume } \%) \text {. } \\
\text { Shade: A1. } \\
\text { Chemicals: }(10-30 \%)\end{array}$ & $\begin{array}{c}\text { Kerr corp, Orange, } \\
\text { CA, USA. }\end{array}$ & A3: 6385712 \\
\hline $\begin{array}{c}\text { Tetric N Ceram } \\
\text { Bulk Fill. }\end{array}$ & 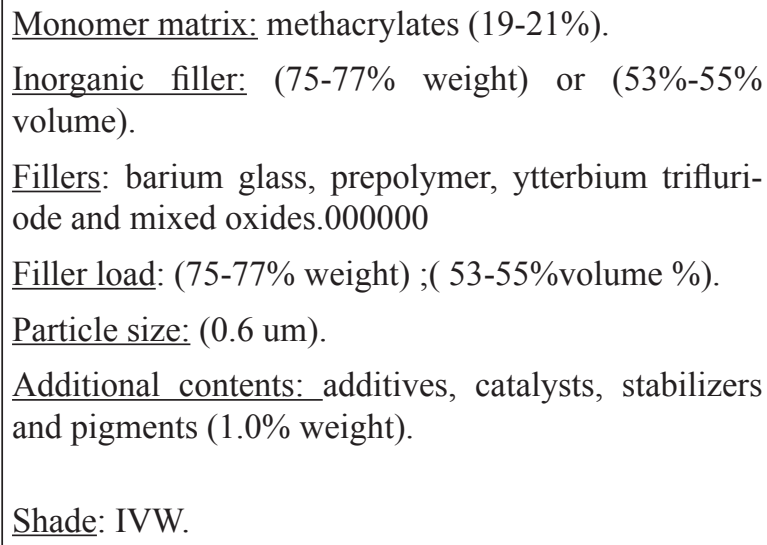 & $\begin{array}{c}\text { Ivoclar Vivadent, } \\
\text { Schaan, Liechtenstein. }\end{array}$ & IVB: T27602 \\
\hline
\end{tabular}




\section{A. Polymerization shrinkage strains measurements:}

Sixty discs, were fabricated using three split Teflon moulds, with dimensions; $(6 \mathrm{~mm}$ in diameter \& $2 \mathrm{~mm}, 4 \mathrm{~mm}$ and $6 \mathrm{~mm}$ in depth), each mould was encircled by a copper ring to provide stabilization during manipulation of the materials. The discs divided in to two groups according to the restorative materials used: Sonic Fill and Tetric N Ceram resin composites, and each subgroup in turns divided in to three groups based on specimen thickness $(n=10)$. A glass slab served as a base for the baseless Teflon split mould, the strain guage foil was attached to the glass slab surface, with the stain guage in place under the mould, the mould was filled with the two tested resin composites. The Sonic Fill handpiece was accurately positioned on the Multiflex coupling and both of them were attached to the portable motor, the unidose Sonic Fill capsule was inserted to Sonic Fill handpiece. The unidose capsules was placed at the deepest point of the mould to avoid air trapping, Sonic Fill handpiece was activated by depressing foot pedal and the mould was filled up to the end. Tetric $\mathrm{N}$ Ceram was expressed out of the syringe and was adapted into the moulds manually in bulk using gold plated instruments. A piece of clear matrix was applied over the upper surface of the mould, and then a glass cover was placed over it and was pressed using a $50 \mathrm{~g}$ weight. After removal of the glass cover and the matrix, the excess leaked out composite was removed, then the resin composite was cured. The curing tip of the light conductor was perpendicular to the composite surface at zero distance using light emitted diode (LED) at wave length range of 440$480 \mathrm{~nm}$, and light intensity $1,200 \mathrm{~mW} / \mathrm{cm}^{2}$, for 20 secs. The strain guage foil was in direct contact to a strain monitoring device which was initially balanced at zero and was connected to the computer software program ${ }^{(7)}$.

\section{Depth of cure:}

After measuring the polymerization shrinkage, all specimens were detached from the Teflon moulds. Then they were finished and polished using soflex discs. Then were stored dry for $24 \mathrm{~h}$ at $37^{\circ} \mathrm{C}$ in dark container. A dark marker pen was used to identify the top surface of each specimen. A Vickers hardness tester was used to measure the microhardness of the top and bottom surfaces of each specimen. The measuring indenter, (the Vickers pyramid) was pressed to the composite specimen using a $50 \mathrm{~g}$ load with a 10 seconds dwell time, the surface Vickers hardness was measured at three points of each surface. The surfaces of each specimen were examined under a magnifying lens. The corresponding Vickers Hardness Number values were taken from specially designed tables supplied with Vickers Hardness machine. The mean of the sum of indentations per surface was calculated to have one representative reading for both the bottom and top surface hardness, depth of cure percentage calculated according to the following equation ${ }^{(8)}$.

$$
\text { Depth of cure }(\%)=\frac{\text { Bottom microhardness }}{\text { Top microhardness }} \times 100^{(8)}
$$

\section{B. Degree of conversion: (KBR pellet technique)}

The uncured specimens were prepared by taking 4 $\mathrm{mg}$ resin composite from the resin composite syringe using a digital micro balance then were diluted in $2 \mathrm{~mm}$ of chloroform, then smeared between two potassium bromide crystals. They were placed into a cell holder in the FTIR spectrometer (Fourier transform infrared spectroscopy). The cured specimens after the previous test were crushed manually in a gate mortar. An amount of $4 \mathrm{mg}$ of the resin composite powder were mixed with $196 \mathrm{mg}$ of pure potassium bromide (KBR) to get a concentration of $1.5 \%$ sample to KBR. The mixing was carried out for 2 minutes in a gate mortar. Then the mixture was pressed under vacuum hydraulic press at $80 \mathrm{KN}$ to form a disc of 13 $\mathrm{mm}$ diameter. The discs were inserted in the FTIR spectrometer and then they were exposed to 120 scans at a resolution of $4 \mathrm{~cm}^{-1}$. The infra-red absorption spectra were measured in the frequency region 4000$400 \mathrm{~cm}^{-1}$ against absorbance peak intensities using the software program in the computer connected to the FTIR unit. The degree of conversion for the 
methacrylate-based resin composite was determined according to Rueggeberg's base line method $^{(9)}$ by calculating the peak intensities of aliphatic $\mathrm{C}=\mathrm{C}$ at $1638 \mathrm{~cm}^{-1}$ and aromatic $\mathrm{C}=\mathrm{C}$ at $1608 \mathrm{~cm}^{-1}$, before and after polymerization according to the following equation:

DC $\%=1-\frac{\text { aliphatic } \mathrm{C}=\mathrm{C} / \text { aromatic } \mathrm{C}=\mathrm{C} \text { of polymer }}{\text { aliphatic } \mathrm{C}=\mathrm{C} / \text { aromatic } \mathrm{C}=\mathrm{C} \text { of monomer }} 100 \%{ }^{(10)}$

\section{STATISTICAL ANALYSIS}

Comparison between the two groups was done using student t-test. Comparison of the mean of different specimen's thickness in each material was done using ANOVA test and post Hoc test (Tukey) for pairwise comparisons. Significance level was set at $5 \%$. Statistical analysis was done using IBM SPS statistics version 20.0 .

\section{RESULTS}

\section{Polymerization shrinkage strains:}

At $2 \mathrm{~mm}$ specimen thickness the mean polymerization shrinkage strain resulted in Tetric N Ceram (TNB) were higher than that in Sonic Fill (SF) at all time periods except at $1 \mathrm{sec}$, as shown in (Table 2).

At $4 \mathrm{~mm}$ specimen thickness, the mean polymerization shrinkage strains resulted in (TNB) higher than that in (SF) at all the time periods. There was statistically significant difference between the two materials at all time periods $(\mathrm{P}<0.0001)$, as shown in (Table 3).

Table (2) The mean, standard deviation values, and results of ANOVA test comparing the mean values of the polymerization shrinkage strains of Sonic Fill resin composite $(S F)$ at different specimen thickness and in different time periods.

\begin{tabular}{|c|c|c|c|c|c|}
\hline \multirow{6}{*}{ 豆 } & Time periods & $\begin{array}{c}\text { SF } \\
(n=10)\end{array}$ & $\begin{array}{c}\text { TNB } \\
(n=10)\end{array}$ & $\mathbf{t}$ & $\mathbf{p}$ \\
\hline & $1 \mathrm{Sec}$ & $52.0 \pm 19.75$ & $37.0 \pm 17.51$ & 1.797 & 0.089 \\
\hline & 20 Secs & $-1048.5 \pm 102.66$ & $-1491.0 \pm 123.94$ & $8.695^{*}$ & $<0.001^{*}$ \\
\hline & 80 Secs (1m) & $-1567.5 \pm 55.49$ & $-2306.0 \pm 152.04$ & $14.429^{*}$ & $<0.001^{*}$ \\
\hline & $140 \operatorname{Secs}(2 m)$ & $-1625.0 \pm 70.24$ & $-2368.0 \pm 146.88$ & $14.431^{*}$ & $<0.001^{*}$ \\
\hline & $200 \operatorname{Secs}(3 \mathrm{~m})$ & $-1656.50 \pm 77.07$ & $-2398.0 \pm 146.88$ & $14.137^{*}$ & $<0.001^{*}$ \\
\hline
\end{tabular}

*: Statistically significant at $p \leq 0.05$

Table (3) The mean, standard deviation values, and results of student $t$-test for comparing the mean values of the polymerization shrinkage strains of Sonic Fill resin composite (SF) and Tetric NCeram bulk fill resin composite (TNB) at 4mm specimen thickness in different time periods.

\begin{tabular}{|c|c|c|c|c|c|}
\hline \multirow{6}{*}{ 豆 } & Time periods & $\begin{array}{c}\text { SF } \\
(n=10)\end{array}$ & $\begin{array}{c}\text { TNB } \\
(n=10)\end{array}$ & $\mathbf{t}$ & $\mathbf{p}$ \\
\hline & $1 \mathrm{Sec}$ & $58.0 \pm 11.35$ & $71.0 \pm 8.43$ & $2.907^{*}$ & $0.010^{*}$ \\
\hline & $20 \mathrm{Sec}$ & $-1246.0 \pm 38.21$ & $-1527.0 \pm 100.23$ & $8.284^{*}$ & $<0.001^{*}$ \\
\hline & $80 \operatorname{Sec}(1 \mathrm{~m})$ & $-1604.0 \pm 81.40$ & $-2333.0 \pm 49.68$ & $24.173^{*}$ & $<0.001^{*}$ \\
\hline & $140 \mathrm{Sec}(2 \mathrm{~m})$ & $-1775.2 \pm 68.83$ & $-2419.0 \pm 61.54$ & $22.049^{*}$ & $<0.001^{*}$ \\
\hline & $200 \mathrm{Sec}(3 \mathrm{~m})$ & $-1915.0 \pm 47.43$ & $-2562.0 \pm 102.50$ & $18.115^{*}$ & $<0.001^{*}$ \\
\hline
\end{tabular}

*: Statistically significant at $p \leq 0.05$ 
At $6 \mathrm{~mm}$ specimen thickness, the mean polymerization shrinkage strains resulted in (SF) was lower than that in (TNB) at all time periods. There was no statistically significant difference at 20 secs but there was statistically significant difference at $1 \mathrm{sec}, 80$ secs, 140 secs and $200 \operatorname{secs}(\mathrm{P}<0.0001)$, as shown in (Table 4).

The mean of polymerization shrinkage strains of
Sonic Fill was the highest at $4 \mathrm{~mm}$ specimen thickness followed by the mean values at $2 \mathrm{mmm}$ while the lowest mean values were at $6 \mathrm{~mm}$ at all time periods, as shown in (Table 5).

The mean polymerization shrinkage strains of Tetric N Ceram at $4 \mathrm{~mm}$ were higher than at $2 \mathrm{~mm}$ and $6 \mathrm{~mm}$, and at $2 \mathrm{~mm}$ were higher than at $6 \mathrm{~mm}$ at all time periods, as shown in (Table 6).

Table (4): The mean, standard deviation values, and results of student $t$-test for comparing the mean values of the polymerization shrinkage strains of Sonic Fill resin composite (SF) and Tetric N Ceram bulk fill resin composite (TNB) at $6 \mathrm{~mm}$ specimen thickness in different time periods.

\begin{tabular}{|c|c|c|c|c|c|}
\hline \multirow{2}{*}{ Time periods } & $\begin{array}{c}\text { SF } \\
(\mathbf{n}=\mathbf{1 0})\end{array}$ & $\begin{array}{c}\text { TNB } \\
\mathbf{( n = 1 0 )}\end{array}$ & $\mathbf{t}$ & $\mathbf{p}$ \\
\cline { 2 - 6 } & $\mathbf{1 ~ S e c}$ & $22.0 \pm 15.13$ & $48.0 \pm 20.44$ & $3.233^{*}$ & $0.005^{*}$ \\
\cline { 2 - 6 } & $\mathbf{2 0 ~ S e c}$ & $-465.0 \pm 159.65$ & $-554.0 \pm 206.41$ & 1.079 & 0.295 \\
\cline { 2 - 6 } & $\mathbf{8 0 ~ S e c ~ ( 1 m ) ~}$ & $-830.0 \pm 69.60$ & $-1078.0 \pm 88.36$ & $6.972^{*}$ & $<0.001^{*}$ \\
\cline { 2 - 6 } & $\mathbf{1 4 0 ~ S e c ~ ( 2 m ) ~}$ & $-939.0 \pm 90.70$ & $-1158.0 \pm 91.81$ & $5.366^{*}$ & $<0.001^{*}$ \\
\hline
\end{tabular}

*: Statistically significant at $p \leq 0.05$

Table (5): The mean, standard deviation values, and results of ANOVA test comparing the mean values of the polymerization shrinkage strains of Sonic Fill resin composite (SF) at different specimen thickness and in different time periods.

\begin{tabular}{|c|c|c|c|c|c|}
\hline Time periods & $\begin{array}{c}\mathbf{2 m m} \\
\mathbf{( n = 1 0 )}\end{array}$ & $\begin{array}{c}\mathbf{4 m m} \\
\mathbf{( n = 1 0 )}\end{array}$ & $\begin{array}{c}\mathbf{6 m m} \\
\mathbf{( n = 1 0 )}\end{array}$ & $\mathbf{F}$ & $\mathbf{p}$ \\
\hline $\mathbf{1 ~ S e c}$ & $52.0^{\mathrm{a}} \pm 19.75$ & $58.0^{\mathrm{a}} \pm 11.35$ & $22.0^{\mathrm{b}} \pm 15.13$ & $14.924^{*}$ & $<0.001^{*}$ \\
\hline $\mathbf{2 0 ~ S e c}$ & $-1048.5^{\mathrm{b}} \pm 102.66$ & $-1246.0^{\mathrm{a}} \pm 38.21$ & $-465.0^{\mathrm{c}} \pm 159.65$ & $131.967^{*}$ & $<0.001^{*}$ \\
\hline $\mathbf{8 0 ~ S e c ~ ( 1 m ) ~}$ & $-1567.5^{\mathrm{b}} \pm 55.49$ & $-1604.0^{\mathrm{a}} \pm 81.40$ & $-830.0^{\mathrm{c}} \pm 69.60$ & $393.228^{*}$ & $<0.001^{*}$ \\
\hline $\mathbf{1 4 0} \mathbf{~ S e c} \mathbf{( 2 m )}$ & $-1625.0^{\mathrm{b}} \pm 70.24$ & $-1775.2^{\mathrm{a}} \pm 68.83$ & $-939.0^{\mathrm{c}} \pm 90.70$ & $333.103^{*}$ & $<0.001^{*}$ \\
\hline $\mathbf{2 0 0} \mathbf{S e c} \mathbf{( 3 m )}$ & $-1656.5^{\mathrm{b}} \pm 77.07$ & $-1915.0^{\mathrm{a}} \pm 47.43$ & $-1000.0^{\mathrm{c}} \pm 88.94$ & $414.601^{*}$ & $<0.001^{*}$ \\
\hline
\end{tabular}

*: Statistically significant at $p \leq 0.05$, mean with different superscripts letters are statistically significant different. 
Table (6): The mean, standard deviation values, and results of ANOVA test comparing the mean values of the polymerization shrinkage strains of Tetric $N$ Ceram bulk fill resin composite (TNB) at different specimen thickness and in different time periods.

\begin{tabular}{|c|c|c|c|c|c|}
\hline Time periods & $\begin{array}{c}\mathbf{2 m m} \\
\mathbf{( n = 1 0 )}\end{array}$ & $\begin{array}{c}\mathbf{4 m m} \\
\mathbf{( n = 1 0 )}\end{array}$ & $\begin{array}{c}\mathbf{6 m m} \\
\mathbf{( n = 1 0 )}\end{array}$ & $\mathbf{F}$ & $\mathbf{p}$ \\
\hline $\mathbf{1 ~ S e c}$ & $48.0^{\mathrm{b}} \pm 20.44$ & $71.0^{\mathrm{a}} \pm 8.43$ & $37.0^{\mathrm{b}} \pm 17.51$ & $11.351^{*}$ & $<0.001^{*}$ \\
\hline $\mathbf{2 0} \mathbf{S e c}$ & $-1491.0^{\mathrm{a}} \pm 123.94$ & $-1527.0^{\mathrm{a}} \pm 100.23$ & $-554.0^{\mathrm{b}} \pm 206.41$ & $134.245^{*}$ & $<0.001^{*}$ \\
\hline $\mathbf{8 0 ~ S e c ~ ( 1 m ) ~}$ & $-2306.0^{\mathrm{a}} \pm 152.04$ & $-2333.0^{\mathrm{a}} \pm 49.68$ & $-1078.0^{\mathrm{b}} \pm 88.36$ & $461.776^{*}$ & $<0.001^{*}$ \\
\hline $\mathbf{1 4 0} \mathbf{S e c}(\mathbf{2 m})$ & $-2368.0^{\mathrm{a}} \pm 146.88$ & $-2419.0^{\mathrm{a}} \pm 61.54$ & $-1158.0^{\mathrm{b}} \pm 91.81$ & $452.326^{*}$ & $<0.001^{*}$ \\
\hline $\mathbf{2 0 0} \mathbf{S e c} \mathbf{( 3 m )}$ & $-2398.0^{\mathrm{b}} \pm 146.88$ & $-2562.0^{\mathrm{a}} \pm 102.5$ & $-1194.0^{\mathrm{c}} \pm 94.83$ & $407.556^{*}$ & $<0.001^{*}$ \\
\hline
\end{tabular}

*: Statistically significant at $p \leq 0.05$, mean with different superscripts letters are statistically significant different.

\section{Depth of cure (Vickers hardness Number):}

The highest mean value of depth of cure was recorded in Sonic Fill resin composite at $2 \mathrm{~mm}$ specimen thickness $(98.04 \pm 0.32)$ and the lowest mean value of depth of cure was recorded in Tetric $\mathrm{N}$ Ceram bulk fill resin composite at $6 \mathrm{~mm}$ specimen thickness (78.37 \pm 0.53$)$, as shown in (Table 7).

Table (7): The mean, standard deviation values, and results of student $t$-test for comparing the mean values of depth of cure of Sonic Fill resin composite $(S F)$ and Tetric N Ceram bulk fill resin composite (TNB) at different specimen thickness.

\begin{tabular}{|c|c|c|c|c|}
\hline $\begin{array}{c}\text { Specimen } \\
\text { thickness }\end{array}$ & $\begin{array}{c}\text { SF } \\
(\mathbf{n}=\mathbf{1 0})\end{array}$ & $\begin{array}{c}\text { TNB } \\
(\mathbf{n}=\mathbf{1 0})\end{array}$ & $\mathbf{t}$ & $\mathbf{p}$ \\
\hline $\mathbf{2 m m}$ & $98.04 \pm 0.32$ & $92.02 \pm 0.93$ & $19.328^{*}$ & $<0.001^{*}$ \\
\hline $\mathbf{4 m m}$ & $87.19 \pm 0.48$ & $82.79 \pm 1.58$ & $8.414^{*}$ & $<0.001^{*}$ \\
\hline $\mathbf{6 m m}$ & $80.22 \pm 0.44$ & $78.37 \pm 0.53$ & $8.556^{*}$ & $<0.001^{*}$ \\
\hline
\end{tabular}

*: Statistically significant at $p \leq 0.05$.

Vickers hardness number for Sonic Fill resin composite at all specimen thickness reached the minimum acceptable ratio of $(80 \%)^{(11)}$, where the highest mean value in depth of cure was at $2 \mathrm{~mm}$ specimen thickness followed by the mean values at $4 \mathrm{~mm}$ specimen thickness while the lowest mean values were at $6 \mathrm{~mm}$ specimen thickness, as shown in (Table 8).

Table (8): The mean, standard deviation values, and results of ANOVA test comparing the mean values of depth of cure (VHN) of Sonic Fill resin composite $(S F)$ at different specimen thickness.

\begin{tabular}{|l|c|c|c|c|c|}
\hline Thickness & $\begin{array}{c}\mathbf{2 m m} \\
\mathbf{( n = 1 0 )}\end{array}$ & $\begin{array}{c}\mathbf{4 m m} \\
\mathbf{( n = 1 0 )}\end{array}$ & $\begin{array}{c}\mathbf{6 m m} \\
(\mathbf{n}=\mathbf{1 0})\end{array}$ & $\mathbf{F}$ & $\mathbf{p}$ \\
\hline VHN & $\begin{array}{c}98.04^{\mathrm{a}} \\
\pm 0.32\end{array}$ & $\begin{array}{c}87.19^{\mathrm{b}} \\
\pm 0.48\end{array}$ & $\begin{array}{c}80.22^{\mathrm{c}} \\
\pm 0.44\end{array}$ & $4617.88^{*}$ & $<0.001^{*}$ \\
\hline
\end{tabular}

*: Statistically significant at $p \leq 0.05$, mean with different superscripts letters are statistically significant different.

Vickers hardness number at $2 \mathrm{~mm}$ and $4 \mathrm{~mm}$ specimen thickness reached the minimum acceptable ratio of $(80 \%)^{(11)}$, except at $6 \mathrm{~mm}$ thickness, the depth of cure at $2 \mathrm{~mm}$ specimen thickness had the highest mean value, followed by mean values at $4 \mathrm{~mm}$ thickness while at $6 \mathrm{~mm}$ thickness revealed the lowest mean value), as shown in (Table 9). 
Table (9): The mean, standard deviation values, and results of ANOVA test comparing the mean values of depth of cure (VHN) of Tetric N Ceram bulk fill resin composite (TNB) at different specimen thickness.

\begin{tabular}{|l|c|c|c|c|c|}
\hline Thickness & $\begin{array}{c}\mathbf{2 m m} \\
\mathbf{( n = 1 0 )}\end{array}$ & $\begin{array}{c}\mathbf{4 m m} \\
(\mathbf{n}=\mathbf{1 0})\end{array}$ & $\begin{array}{c}\mathbf{6 m m} \\
\mathbf{( n = 1 0 )}\end{array}$ & $\mathbf{F}$ & $\mathbf{p}$ \\
\hline VHN & $\begin{array}{c}92.02^{\mathrm{a}} \\
\pm 0.93\end{array}$ & $\begin{array}{c}82.79^{\mathrm{b}} \\
\pm 1.58\end{array}$ & $\begin{array}{c}78.37^{\mathrm{c}} \\
\pm 0.53\end{array}$ & $398.305^{*}$ & $<0.001^{*}$ \\
\hline
\end{tabular}

*: Statistically significant at $p \leq 0.05$, mean with different superscripts letters are statistically significant different.

\section{Degree of conversion:}

The highest mean value for degree of conversion was recorded in Sonic Fill resin composite at $2 \mathrm{~mm}$ specimen thickness $(78.83 \pm 0.87 \%)$ and the lowest mean value was recorded in Tetric N Ceram bulk fill resin composite at $6 \mathrm{~mm}$ specimen thickness (49.02 \pm 1.06$)$, as shown in (Table 10).

Table (10): The mean, standard deviation values, and results of student $t$-test for comparing the mean values of degree of conversion (DC\%) of Sonic Fill resin composite (SF) and Tetric $N$ Ceram bulk fill resin composite (TNB) at different specimen thickness.

\begin{tabular}{|c|c|c|c|c|}
\hline $\begin{array}{c}\text { Specimen } \\
\text { thickness }\end{array}$ & $\begin{array}{c}\text { SF } \\
(\mathbf{n}=\mathbf{1 0})\end{array}$ & $\begin{array}{c}\text { TNB } \\
(\mathbf{n}=\mathbf{1 0})\end{array}$ & $\mathbf{t}$ & $\mathbf{p}$ \\
\hline $\mathbf{2} \mathbf{m m}$ & $78.83 \pm 0.87$ & $56.20 \pm 0.29$ & $77.704^{*}$ & $<0.001^{*}$ \\
\hline $\mathbf{4 m m}$ & $75.50 \pm 0.39$ & $55.22 \pm 0.36$ & $120.632^{*}$ & $<0.001^{*}$ \\
\hline $\mathbf{6 m m}$ & $56.41 \pm 0.69$ & $49.02 \pm 1.06$ & $18.425^{*}$ & $<0.001^{*}$ \\
\hline
\end{tabular}

*: Statistically significant at $p \leq 0.05$

The degree of conversion in Sonic Fill resin composite at $2 \mathrm{~mm}$ thickness had the highest mean value, followed by mean values at $4 \mathrm{~mm}$ thickness, while specimens of $6 \mathrm{~mm}$ thickness revealed the lowest mean values), as shown in (Table 11).
Table (11): The mean, standard deviation values, and results of ANOVA test comparing the mean values of degree of conversion (DC\%) of Sonic Fill resin composite $(S F)$ at different specimen thickness.

\begin{tabular}{|c|c|c|c|c|c|}
\hline Thickness & $\begin{array}{c}\mathbf{2 m m} \\
(\mathbf{n}=\mathbf{1 0})\end{array}$ & $\begin{array}{c}\mathbf{4 m m} \\
(\mathbf{n}=\mathbf{1 0})\end{array}$ & $\begin{array}{c}\mathbf{6 m m} \\
(\mathbf{n}=\mathbf{1 0})\end{array}$ & $\mathbf{F}$ & $\mathbf{p}$ \\
\hline DC\% & $\begin{array}{c}78.83^{\mathrm{a}} \\
\pm 0.87\end{array}$ & $\begin{array}{c}75.50^{\mathrm{b}} \\
\pm 0.39\end{array}$ & $\begin{array}{c}56.41^{\mathrm{c}} \\
\pm 0.69\end{array}$ & $3156.63^{*}$ & $<0.001^{*}$ \\
\hline
\end{tabular}

*: Statistically significant at $p \leq 0.05$, mean with different superscripts letters are statistically significant different.

The degree of conversion in Tetric N Ceram bulk fill resin composite at $2 \mathrm{~mm}$ thickness had the highest (DC\%) mean value, followed by mean value at $4 \mathrm{~mm}$ thickness while specimens of $6 \mathrm{~mm}$ thickness revealed the lowest mean value), as shown in (Table 12).

Table (12): The mean, standard deviation values, and results of ANOVA test comparing the mean values of degree of conversion (DC\%) of Tetric $N$ Ceram bulk fill resin composite (TNB) at different specimen thickness.

\begin{tabular}{|l|c|c|c|c|c|}
\hline Thickness & $\begin{array}{c}\mathbf{2 m m} \\
(\mathbf{n = 1 0})\end{array}$ & $\begin{array}{c}\mathbf{4 m m} \\
\mathbf{( n = 1 0 )}\end{array}$ & $\begin{array}{c}\mathbf{6 m m} \\
\mathbf{( n = 1 0 )}\end{array}$ & $\mathbf{F}$ & $\mathbf{p}$ \\
\hline DC\% & $\begin{array}{c}56.20^{\mathrm{a}} \\
\pm 0.29\end{array}$ & $\begin{array}{c}55.22^{\mathrm{b}} \\
\pm 0.36\end{array}$ & $\begin{array}{c}49.02^{\mathrm{c}} \\
\pm 1.06\end{array}$ & $337.645^{*}$ & $<0.001^{*}$ \\
\hline
\end{tabular}

*: Statistically significant at $p \leq 0.05$, mean values with different superscripts letters are statistically significant different.

\section{DISCUSSION}

This study aimed at evaluating: 1-The effect of resin thickness from both (Sonic Fill resin composite \& Tetric N Ceram Bulk Fill resin composite) on; A) Polymerization shrinkage strains, B) Depth of cure, C) Degree of conversion).

Composite resin is converted from a viscous phase in to a rigid or solid material and undergo shrinkage when light cured. The results of conversion of the monomer molecules into a polymer network 
ends with a closer packing of the molecules, when weak Vander Waals forces between monomers are converted into covalent bonds, that resulted in polymerization shrinkage. After the composite is placed within a preparation and bonds to the tooth surface, the polymerized resin creates internal mechanical strains, which is pass in to the tooth bond interface ${ }^{(12)}$.

In the current study, the mean values of polymerization shrinkage strains, regarding specimen thickness, for Sonic Fill resin composite were less than the mean values of shrinkage strains of Tetric $\mathrm{N}$ Ceram bulk fill resin composite at all specimen thickness $92 \mathrm{~mm}, 4 \mathrm{~mm}, 6 \mathrm{~mm})$. This could be explained by, there is a direct relationship between the shrinkage value and the amount of organic matrix in the material ${ }^{(13)}$, and Sonic Fill had an estimated filler content of $83.5 \%$ by weight and $69 \%$ by volume so it has low resin ${ }^{(14)}$. Moreover, the influence of ultrasonic energy on resin curing as the thermal effect of sonic vibration may promote polymerization by increasing free radicals mobility directly and indirectly as a consequence of decreased viscosity ${ }^{(15)}$.

The polymerization shrinkage strains increased with increasing the specimen thickness from $2 \mathrm{~mm}$ to $4 \mathrm{~mm}$. This might be as a result of two reasons: First, due to the increase in the bulk fill resin composites translucency ${ }^{(16)}$. Second, due to high degree of conversion, there was an increase in both polymerization shrinkage and degree of conversion with increasing specimen thickness from $2 \mathrm{~mm}$ to $4 \mathrm{~mm}$ as found in previous study ${ }^{(10)}$. This provided an indication of similar curing through the whole bulk increment, as the degree of conversion is one of the main factors responsible for the magnitude of generated shrinkage stresses ${ }^{(17)}$. However, at $6 \mathrm{~mm}$ specimens thickness, the polymerization shrinkage strains decreased, which could be explained by, the decrease in polymerization shrinkage strains rate resulted from incomplete polymerization ${ }^{(18)}$.

The depth of cure (DOC\%) is the ratio of bottom to surface microhardness of resin composites, and it is widely used to evaluate the irradiance passage within the full depth of dental resin composite ${ }^{(19)}$. The hardness ratio of bottom/ top which is above 80 has often been used as a minimum acceptable threshold ${ }^{(20)}$.

The current results concerning the resin thickness effect on the mean value of Vickers hardness, Sonic Fill succeeded not only to reach but to exceed the minimum acceptable ratio of VHN $(80 \%)^{(20,21)}$, at all specimen thickness. These findings could be explained by the truth of the matter that Sonic Fill had high filler loading ( $83.5 \%$ weight) and, there is a direct proportion between filler loading and Vickers hardness ${ }^{(22)}$.

Concerning the results of the mean values of Vickers hardness number for Tetric N Ceram (TNB) bulk fill resin composite, at $2 \mathrm{~mm}$ and $4 \mathrm{~mm}$ specimens thickness it reached and exceeded the minimum acceptable ratio of (80\%). This might be explained by; the fillers of TNB included pre-polymerized fillers (PPF), which enabled the TNB to accomplish a high filler percentage while preserving a low surface area between organic matrix and inorganic fillers, as a part of PPF is already organic. Increase the translucency leads to increase in the depth of cure, the amount of light transmitted through a composite material depends on the amount of scattered and absorbed light, light scattering is increased in materials with a large filler matrix interface area, due to change in refractive indices between resin matrix filler and particles ${ }^{(20,23-25)}$.

Concerning the effect of increasing the thickness of the specimens on the mean value of VHN, there was a decrease in VHN mean values with increasing the specimen thickness in both Sonic Fill and Tetric $\mathrm{N}$ Ceram resin composites. This could be due to, the lack of light transmission through the composite at greater depths, as a high amount of the wave lengths are absorbed near the superficial surface of the resin composite which could not be enough to excite coinitiators at greater depths ${ }^{(21,26-29)}$. 
The resin matrix consists of a multifunctional long chain monomer which, when polymerized, results in a three-dimensional network of cross-linked bonds known as polymers. DC\% corresponds to the measurement of the percent of double carboncarbon bonds in the polymerization process ${ }^{(30)}$.

Comparing the mean value of DC\% of Sonic Fill and Tetric N Ceram at specimen of different thickness, the results showed that, the DC\% of Sonic Fill was statistically significantly higher than of Tetric N Ceram at all specimen thickness. This difference may be related to the chemical construction of inorganic resin of Sonic Fill that contains 3- trimethoxysilypropyl methacrylate (1030\%), TEGDMA and Bis EMA. These types of monomers are highly flexible, have low molecular weight and low viscosity, Comparing the mean value of DC\% of Sonic Fill and Tetric N Ceram at specimen of different thickness, the results showed that, the DC\% of Sonic Fill was statistically significantly higher than of Tetric N Ceram at all specimen thickness. This difference may be related to the chemical construction of inorganic resin of Sonic Fill that contains 3- trimethoxysilypropyl methacrylate (10-30\%), TEGDMA and Bis EMA. These types of monomers are highly flexible, have low molecular weight and low viscosity ${ }^{(10)}$.

\section{CONCLUSIONS}

Under the limitations of the present study, the following conclusion could be delivered:

Degree of conversion, depth of cure and polymerization shrinkage were affected by material thickness thus the null hypothesis is rejected.

\section{REFERENCES}

1. Pilo R, Oelgiesser D, and Cardash HS. A survey of output intensity and potential for depth of cure among light-curing units in clinical use. J Dent. 1999; 27: 235-41.

2. Flurya S, Hayozb S, Peutzfeldt A, Hüslerb J, and Lussia A. Depth of cure of resin composites: Is the ISO 4049 method suitable for bulk fill materials. J Dent Mat. 2012; 28-521.
3. Sonic Fill Portfolio. Retrieved online from: https://www. kerrdental.com/resource-center/sonicfill-portfolio-scientific-research.

4. Lazarchik D, Hammond B, Sikes C, Looney S, and Rueggeberg F. Hardness comparison of bulk filled/Trans tooth and incremental-filled/occlusally irradiated resin composites. J Prosthet Dent 2007; 98: 129-34.

5. Sideridou ID and Achilias DS. Elution study of unreacted Bis-GMA, TEGDMA, UDMA, and Bis-EMA from lightcured dental resins and resin composites using HPLC. J Biomed Mater Res B Appl Bio mater 2005; 74: 617-26.

6. Tiba A, Zeller GG, Estrich C, and Hong A. A Laboratory Evaluation of Bulk fill versus Traditional Multi-IncrementFill Resin-Based Composites. J Am Dent Assoc. 2013; 144: 1182-3.

7. Damineni R, Shailendra M A, and Reddy G Sh. Evaluation of polymerization shrinkage of light cured composite resins. Advances in Human Biology. 2014; 4: 26-30.

8. Kim E H, Jung K H, Son S A, Hur B, Kwon Y H and Park J $\mathrm{K}$. Effect of resin thickness on the microhardness and optical properties of bulk fill resin composites. J Restor Dent Endod. 2015; 40: 128-35.

9. Rueggeberg FA, Hashinger DT, and Fairhurst CW. Calibration of FTIR conversion analysis of contemporary dental resin composites. J Dental Materials. 1990; 6: 241-9.

10. Yu P, Yap A U J, and Wang X Y. Degree of Conversion and Polymerization Shrinkage of Bulk- Fill Resin-Based Composites. J Operative Dentistry. 2017; 42: 82-89.

11. Kim EH, Jung KH, Son SA, Hur B, Kwon YH and Park JK. Effect of resin thickness on the microhardness and optical properties of bulk fill resin composites. J Restor Dent Endod. 2015; 40: 128-35.

12. Ferrancane JL. Developing a more complete understanding of stresses produced in dental composites during polymerization. J Dent Mater. 2005; 21: 36-42.

13. Rodriguez VI, Abate PF and Macchi RL. Immediate polymerization shrinkage in light cured restorative resins. Acta Odontologica Lantinoamericana. 2006; 19: 3-7.

14. Giachetti L, Bertini F, Bambi C and Scaminaci Russo D. A rational use of dental materials in posterior direct resin restorations in order to control polymerization shrinkage stress. Miner Stomat. 2007; 56: 129-38.

15. Alshali RZ, Silikas N, and Satterthwaite JD. Degree of conversion of bulk-fill compared to conventional resin composites at two time intervals. J Dent Mater. 2013;29: 213-77. 
16. El-Damanhoury HM, and Platt JA. Polymerization Shrinkage Stress Kinetics and Related Properties of Bulkfill Resin Composites. J Operative Dentistry. 2013; 39-41.

17. Chen HY, Manhart J, Hickel R and Kunzelmann KH Polymerization contraction stress in light-cured packable composite resins. J Dental Materials. 2001;17: 253-9.

18. Son S A, Roh H M, Hur B, Kwon Y H, and Park J K. The effect of resin thickness on polymerization characteristics of silorane-based composite resin. J Restor Dent Endod. 2014; 39: 310-8.

19. Agrawal A, Manwar NU, and Hegde S. Comparative evaluation of surface hardness and depth of cure of silorane and methacrylate based posterior composite resin: An in vitro study. J Conserv Dent. 2015; 18: 136-9.

20. Czasch P, and Ilie N. Invitro comparison of mechanical properties and degree of cure of bulk fill composites. J Clin Oral Investing. 2013; 17:227-35.

21. Kim EH, Jung KH, Son SA, Hur B, Kwon YH and Park JK. Effect of resin thickness on the microhardness and optical properties of bulk fill resin composites. J Restor Dent Endod. 2015; 40: 128-35.

22. Kim KH, Ong JL, and Okuno O. The effect of filler loading and morphology on the mechanical properties of contemporary composites. J Prost Dent. 2002; 87: 642-9.

23. Arikawa H, Kanie T, and Fujii K. Effect of filler properties in composite resins on light transmittance characteristics and color. Dent Mater J. 2007; 26:38-44.
24. Ilie N, Bucuta S, and Draenert M. Bulk fill resin based composites: an in vitro assessment of their mechanical performance. J Oper Dent. 2013; 38:618-25

25. Bucuta $\mathrm{S}$, and Ilie N. Light transmittance and micro-mechanical properties of bulk fill vs. conventional resin based composites. J Clin Oral Investig. 2014; 18:1991-2000

26. Fujita K, Nishiyama N, Nemoto K, Okada T, and Ikemi T. Effect of base monomer's refractive index of curing depth and polymerization conversion of photocured resin composites. J Dent Mat. 2005; 24: 403-8.

27. Garcia D, Yaman P, Dennison J, and Neiva G. Polymerization shrinkage and depth of cure of bulk fill flowable composite resins. J Oper Dent. 2014; 39:441-8.

28. Farahat F, Daneshkazemi A, and Hajiahmadi Z. The Effect of Bulk Depth and Irradiation Time on the Surface Hardness and Degree of Cure of Bulk-Fill Composites. J Dent Biomater, 2016; 3: 284-91

29. Saamah AN, Said AS, and Yahya NA. Depth of Cure and Mechanical Properties of Bulk-Fill Posterior Dental Composites. J Annals of Dentistry. 2018; 1: 11-6.

30. Korichi A, Mouzali M, and Watts DC. Effects of monomer ratios and highly radiopaque fillers on degree of conversion and shrinkage-strain of dental resin composites. J Dent Mater. 2009; 25:1411-8.

31. Tarle Z, Attin T, Marovic D, Andermatt L, Ristic M, and Tauböck TT. Influence of irradiation time on subsurface degree of conversion and microhardness of high-viscosity bulkfill resin composites. J Clin Oral Investing, 2015; 19: 831-40. 